\title{
Editorial
}

\section{Fibrosis quística en pediatría y compromiso ponderoestatural}

La fibrosis quística del páncreas, entidad hereditaria, autosómica recesiva, producto de las mutaciones en el gen que codifica la proteína reguladora de la conductancia transmembrana, es una entidad que si no se diagnóstica a tiempo es desvastadora desde el punto de vista nutricional.

El compromiso de la fibrosis quística en el niño es multisistémico, principalmente respiratorio y digestivo (intestino, páncreas, hígado), que repercute en lo nutricional, y por ende la calidad de vida de los niños.

El estudio de Jassim et al., presentado en este suplemento, busca evaluar el grado de afectación del crecimiento pondoestatural como efecto de la fibrosis quística del páncreas en los infantes que asisten a las IPS en Barranquilla entre 2013-2015.
Jassim-Álvarez BR, Sara-Quintero MA. Evaluación del grado de afectación del crecimiento pondoestatural como efecto de la fibrosis quística pancreática en infantes de 0 días de nacidos hasta los 18 años, que asisten a las Instituciones Prestadoras de Salud en Barranquilla (Centro de Atención Pulmonar: Clínica Porto Azúl) entre 2013-2015. Rev Gastrohnup 2015; 17 (3) Supl. 3: S5-S12

\section{CARLOS ALBERTO VELASCO BENÍTEZ \\ Editor \\ Director del Grupo de Investigación en \\ Gastroenterología, Hepatología y Nutrición \\ Pediátrica GASTROHNUP \\ Profesor Titular \\ Universidad del Valle}

Cali, diciembre 15 de 2015 


\section{Vía aérea y gases arteriales en pediatría}

Es necesario conocer la anatomía y la fisiología de la vía aérea del niño para entender un poco acerca de la interpretación paraclínica de los gases arteriales.

Hay diferencias importantes entre el adulto y el niño con relación a la vía aérea. Los niños son más susceptibles a presentar problemas que se originan en la vía aérea, incluso, en la edad pediátrica su presentación es más severa.

Cuando se compromete la vía aérea del niño por diversas patologías, uno de los varios paraclinicos con los que contamos para conocer la homeostasis del cuerpo, su equilibrio acido base, la función respiratoria y renal del niño comprometido, son los gases sanguineos, y de su interpretación dependen importantes decisiones clínicas para el abordaje integral del paciente comprometido.
Los artículos de interés propuestos por Jiménez y Alarcón, en este suplemento, describen la anatomía de la vía aérea del niño, los procesos fisiopatológicos que pueden comprometer el sistema respiratorio del niño y la interpretación de los gases sanguíneos como parte del compromiso metabólico.

Jiménez A, Pardo E, Alarcón J. Manejo de la vía aérea pediátrica. Rev Gastrohnup 2015; 17 (3) Supl. 3: S

Alarcón J. Gases sanguíneos y la acidosis metabólica: un abordaje sencillo. Rev Gastrohnup 2015; 17 (3) Supl. 3: S

\section{SANDRALUCÍALOZANO ÁLVAREZ \\ Profesora Auxiliar \\ Programa de Atención Prehospitalaria \\ Universidad del Valle}

Cali, diciembre 15 de 2015 